\title{
PETRI NET MODEL IN THE PROCESS OF SUBMISSION FOR CUSTOMER CREDIT OF BPR LAMBANG GANDA SERANG
}

\author{
Megawati Octavia $^{1}$, Fitriani $^{2 *}$, Ahmad Faisol $^{3}$ \\ ${ }^{1,2}$ Department of Mathematics, Faculty of Mathematics and Natural Sciences, Universitas Lampung \\ Jln. Prof. Sumantri Brodjonegoro, Bandar Lampung, 35145, Indonesia \\ Corresponding author e-mail: ${ }^{2 *}$ fitriani.1984@fmipa.unila.ac.id
}

\begin{abstract}
The credit application process is one of a service that involves queues. This study aims to determine the design of the credit process application service system at the Lambang Ganda Serang Credit Bank using the Petri Net model. This study has 12 places, eight transitions, six operators, and 22 arcs of Petri Net model from credit application service system using Woped 3.2.0 version software.
\end{abstract}

Keywords: credit process application, Petri Net, WOPED.. 


\section{INTRODUCTION}

In every activity, whether in a hospital, shopping center, gas station, Bank, a situation occurs where a person is required to wait to get a service process. The service process is a stage associated with a person's arrival at a service facility, then waiting for the service facility process to finally leave the facility. The activity waiting in order to get a service is called queuing. The queuing theory was first put forward by A. K. Erlang[1], a Danish mathematician who published an article entitled "Solution of Some Problems in the Theory of Probability of Significance in Automatic Telephone Exchange" in 1917. Queuing theory is a module theory that applies a mathematical study of waiting lines, which is a line from customers who need service from an available system [2]. At the Lambang Ganda Serang Rural Bank, the service process is used when customers apply for credit, deposit payments, and deposit savings. When a customer applies for credit, some steps must be taken. Therefore, it is crucial to have a bank customer service system flow so that there is no chaos when making transactions or services at the Bank to form the Petri Net model.

Petri Net is a mathematical model for discrete event systems [3]. Petri Net can model and algebraically analyze transportation networks [4][5][6], manufacturing systems [7][8], agriculture [9][10][11], geography [12][13], and E-commerce [14][15]. Petri Net or Petri Network has been designed mainly to be used for modeling. Petri Net is a direct bipartite graph [16] that has 2 points which are called places and transitions. Arrows represent arcs, the place is represented as circles, and Transitions are represented as rectangles. Arc indirectly connects places with places or transitions with transitions but connects places with transitions or transitions with places. Each place can contain one or more tokens represented by dots, materials, or materials transferred in a Petri Net system [17]. According to [18], Petri Net is said to be pure if it does not have a place that is both input and output for a transition.

Petri net can be represented in two matrices called backward incidence and forward incidence. These two matrices are of size $\mathrm{n} \times \mathrm{m}$, where $\mathrm{n}$ is the number of places and $\mathrm{m}$ is the number of transitions. The elements of this matrix are non-negative integers [19]. The elements in the backward incidence matrix are the arc weights that connect the place to the transition, while the elements in the forward incidence matrix are the arc weights that connect the transition to the place. If there is no arc connecting the place to the transition, then the arc weight is filled with zero [20].

Using the Petri Net theory, a system can be modeled into a Petri network, a mathematical representation of the system. By analyzing the Petri network, it is expected that important information is obtained about the dynamic structure and behavior of the system being modeled and proposes the necessary improvements and changes. Therefore, the authors intend to research and analyze the credit application service process system at BPR Lambang Ganda Serang, which is time-linked with the Petri Net.

\section{METHOD}

This research method uses the library method to collect data about the credit application service process system through literature studies. The research location was conducted at BPR Lambang Ganda Serang. The following are the stages of the research as follows:

1. Study literature by studying references to understand the theories to be used and also information on credit application service process system,

2. Collecting the necessary secondary data, such as data on the credit application service process system at BPR Lambang Ganda Serang.,

3. Make a process flow chart to facilitate the Petri Net modeling process,

4. Make a Petri Net model,

5. Perform simulations using WOPED 3.2.0 software for verification and validation of the Petri Net model,

6. Determine the representation of the matrix,

7. Conclusion. 


\section{RESULTS AND DISCUSSION}

\subsection{Analysis of Petri Net Modeling Service Process System for Customers Applying for Credit at PT BPR Lambang Ganda Serang}

Bank Perkreditan Rakyat Lambang Ganda Serang has 3 products, including savings, credit and time deposits. There are two service facilities available at BPR Lambang Ganda Serang, including savings and time deposit services, credit service facilities. However, what will be discussed in this research is the topic of the process of applying for credit. There is one service facility in applying for credit, but the process consists of several processes. Non-customer bank officers undertake this process.

When the Customer arrives at the Bank, what the credit administration officer does is allowing the Customer to take part in the initial registration by completing the documents. When the files are complete, the following process will be carried out; namely, the Officer will bring the files to be examined by the financial service information system administrator. If the checking process is approved, the following process will wait for the other registration process. However, if the checking process is not approved, return to the initial registration. After the other registration process is running, the following process waits for verification by the Risk Management Executive Officer. If the verification is successful, the following process is carried out by conducting a survey submitted to the marketing department. However, if the verification process is not successful, return to further registration. After the verification process runs, the following process is a small meeting attended by Directors and Marketing regarding credit application decisions. If the decision is approved, the following process will be carried out, namely, waiting for the credit agreement submitted by the credit administration. However, the file is only used as an archive and re-starts from the initial registration if it is not approved.

Based on the analysis that has been carried out at the Lambang Ganda Serang People's Credit Bank, a queuing process model and a flow chart for credit application services are obtained. The queue process model for credit application service queues can be written as:

1. The Customer arrives.

2. Customer follows initial registration.

3. The SLIK administrator checks the completeness of the files.

4. If the files are complete, the SLIK administrator will instruct the Customer to register further. If the file is incomplete, the SLIK administrator is idle.

5. After the files are complete, check the additional registration.

6. The Executive Officer of the Risk Management section checks the completeness of the follow-up registration file so that it can be verified.

7. If the verification is successful, a survey will be carried out, but if the verification is not successful, then the Executive Officer of Risk Management is idle.

8. Marketing officer checks the file so that a survey can be carried out. If the file is complete, the marketing officer will conduct a survey. If the file is incomplete, marketing is idle.

9. After the survey has been successfully carried out, and a small meeting is held to discuss applying for credit.

10.If the small meeting discussion is successfully approved, a decision is made to apply for credit by the marketing officer. However, if it is not approved, the marketing officer is idle.

11.If there is a complete file, then the process is complete, the credit administrator directs the Customer to wait for credit approval. However, if the completeness of the file does not occur, then the credit administrator is idle.

\section{Customers get credit.}

The queuing model can be presented in the form of flow charts and Petri Net networks. 


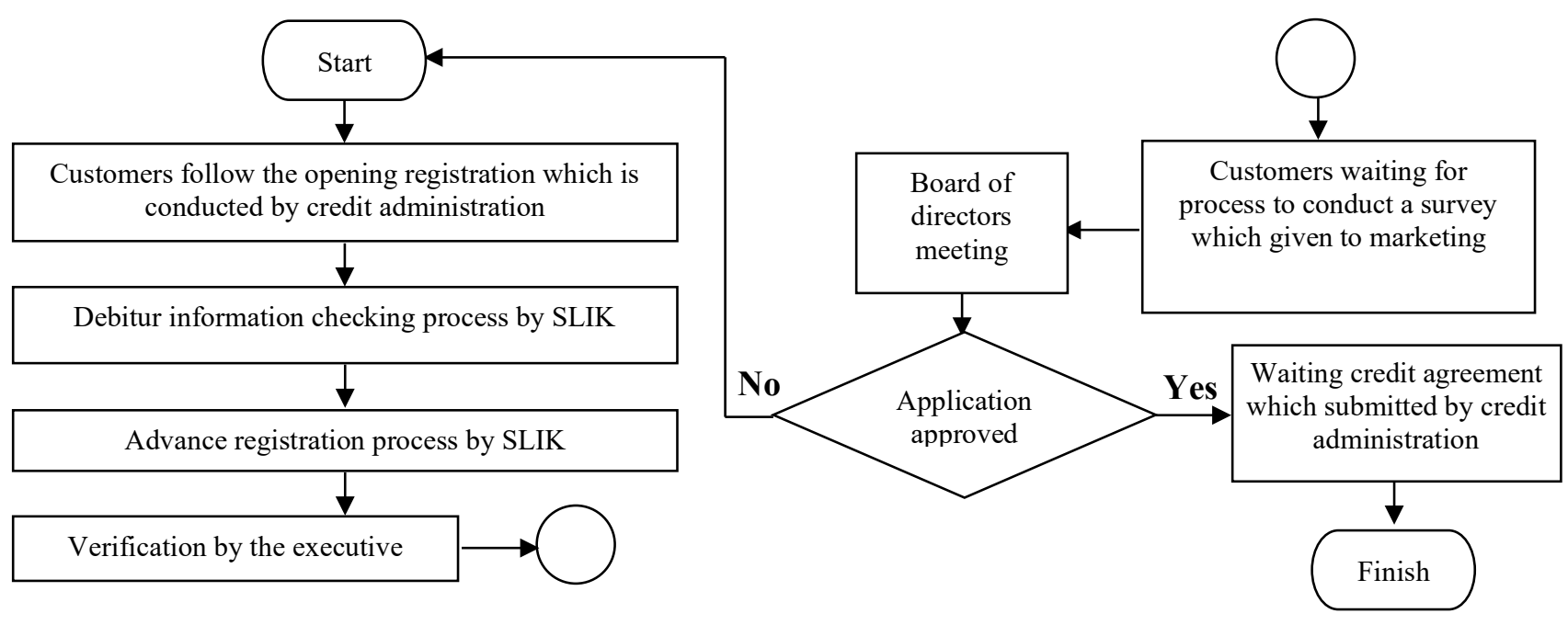

Figure 1. Flow Chart of Credit Application Service Process

\subsection{Petri Net Model}

A Customer Requesting Credit Process Service Model can be formed from the process stages that have been obtained, which is simulated into the Petri Net using the WOPED version 3.2.0 software. The Petri Net model of the Customer Process Service for Credit Applications is presented in a picture consisting of 12 places and eight transitions. This Petri Net starts with the place because tokens that are in transition will run if they have previously been flowed by place so that the arc can be connected.

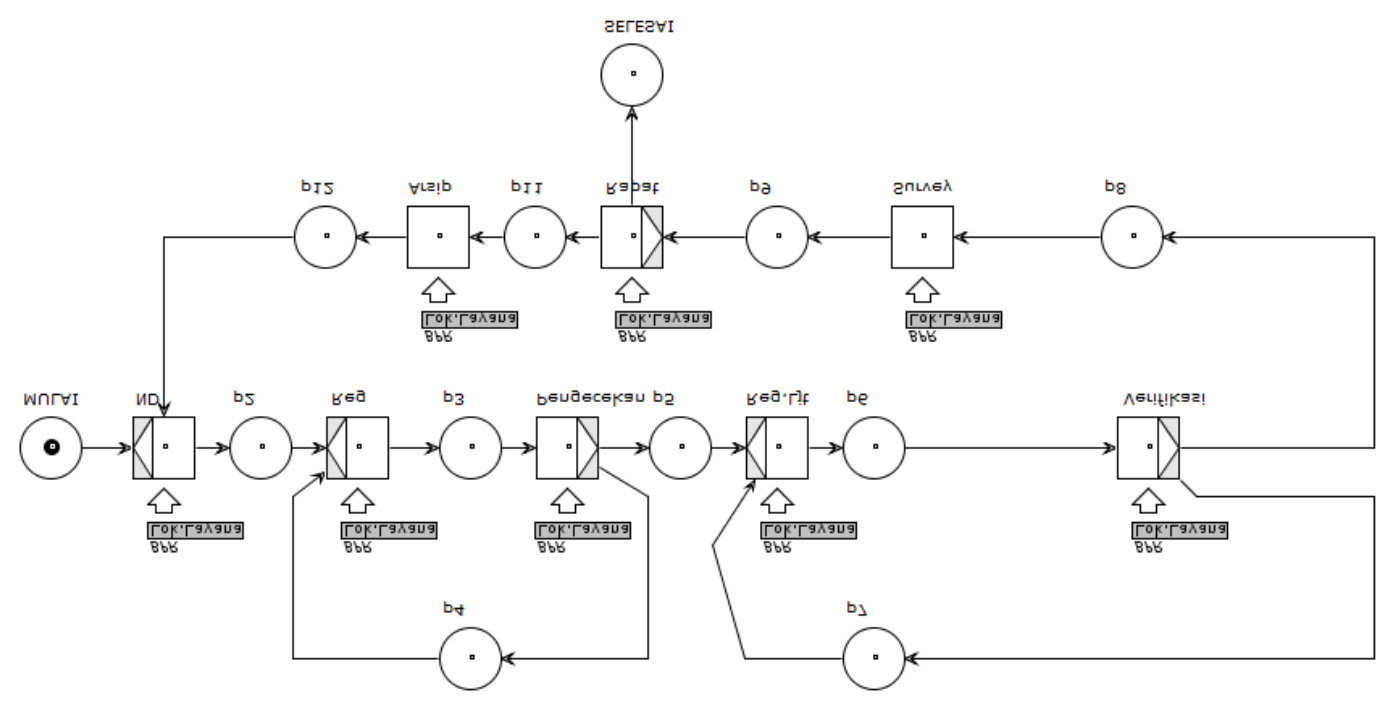

Figure 2. Petri Net Flow of Credit Application Service Process

Information :

$p_{1}=$ Start

$p_{2}=$ Process customers come

$p_{3}=$ Initial registration customer is ready to be served by credit administration officers

$p_{4}=$ Officer idle because initial registration failed

$p_{5}=$ Checking file

$p_{6}=$ Advanced registration

$p_{7}=$ Officer idle because verification failed

$p_{8}=$ Verification was successful

$p_{9}=$ Survey

$p_{10}=$ Finsih $p_{11}=$ Meeting approved

$p_{12}=$ Filing because the meeting was not approved

$t_{1}=$ Customer arrives at the Bank

$t_{2}=$ Initial registration process

$t_{3}=$ Checking debtor information

$t_{4}=$ Advanced registration

$t_{5}=$ Verify

$t_{6}=$ Survey

$t_{7}=$ Meeting

$t_{8}=$ Archiving 
Furthermore, the flow diagram converted to Petri Net is analyzed using Woped with the results shown in Figure 3.

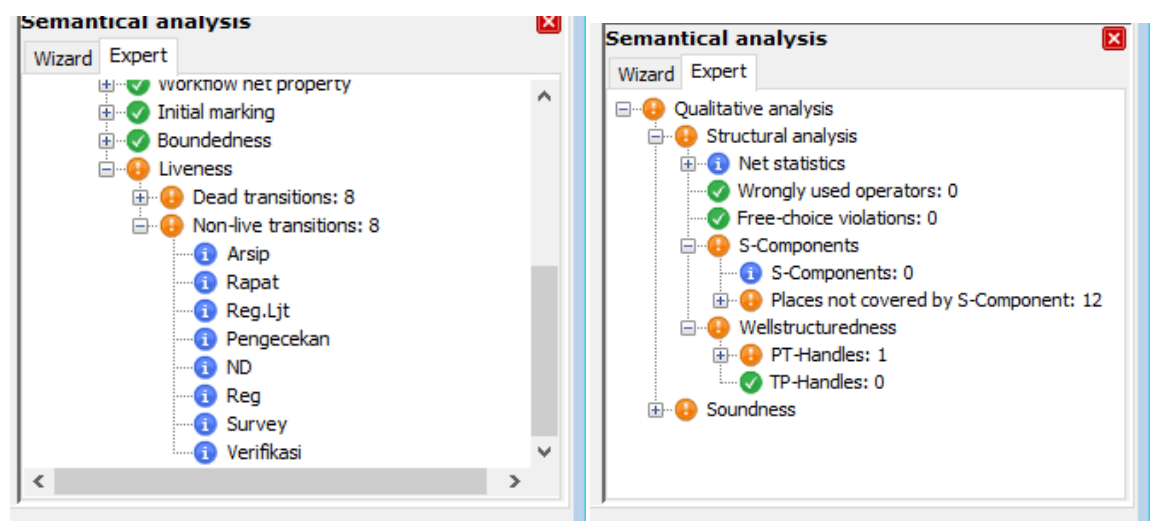

Figure 3. Structural Analysis and Liveness Petri Net Analysis of Credit Application Service Process Systems

Petri Net is used as a formal modeling language for analyzing workflow models to analyze business processes or workflows. Workflows in Petri Net can be verified using the woflan tool to determine if the workflow is sound. A workflow is said to be sound if it is free from deadlocks and livelocks. Soundness is the essential requirement to declare the success of a workflow. A business process is said to be a deadlock if at some point in the workflow process it is no longer possible for a process to occur (deadlock occurs), while livelock occurs if the workflow is always possible to carry out the process continuously, without progress in the process and without ending in a deadlock. or there is an infinite loop

After semantical analysis, a process causes 1 PT-Handle to result in unfulfilled well-structuredness and non-live transitions. The picture will explain the error that caused the PT-Handle from the Petri Net diagram of the Credit Application Service Process.

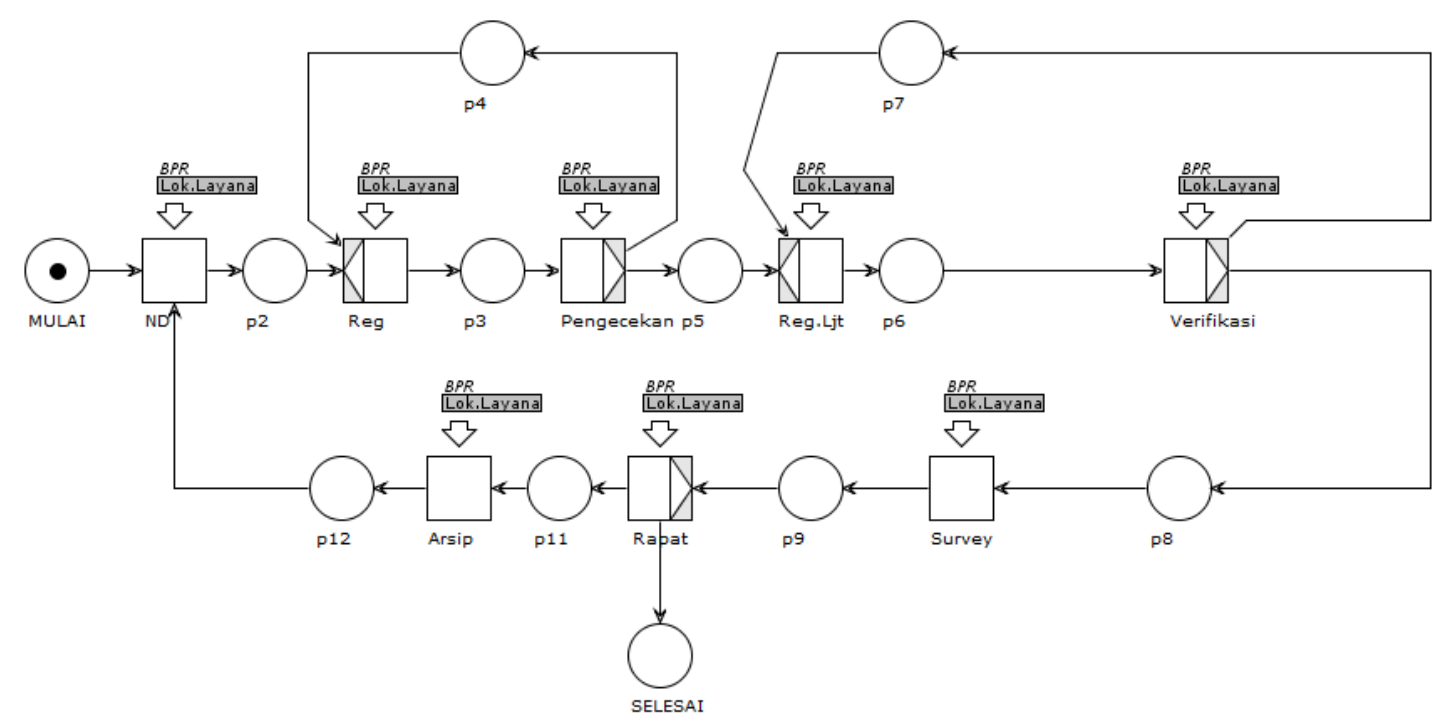

Figure 4. Petri Net Flow Error in Credit Application Service Process System

After analyzing, it is found that the ND statement must have an XOR join element for the first transition. Where if there is an XOR split, it will be closed with an XOR join. The way to calculate the split XOR is by "source" on the place element, with "target" on the transition element. The number of XOR splits corresponds to the target number of the transition element. 


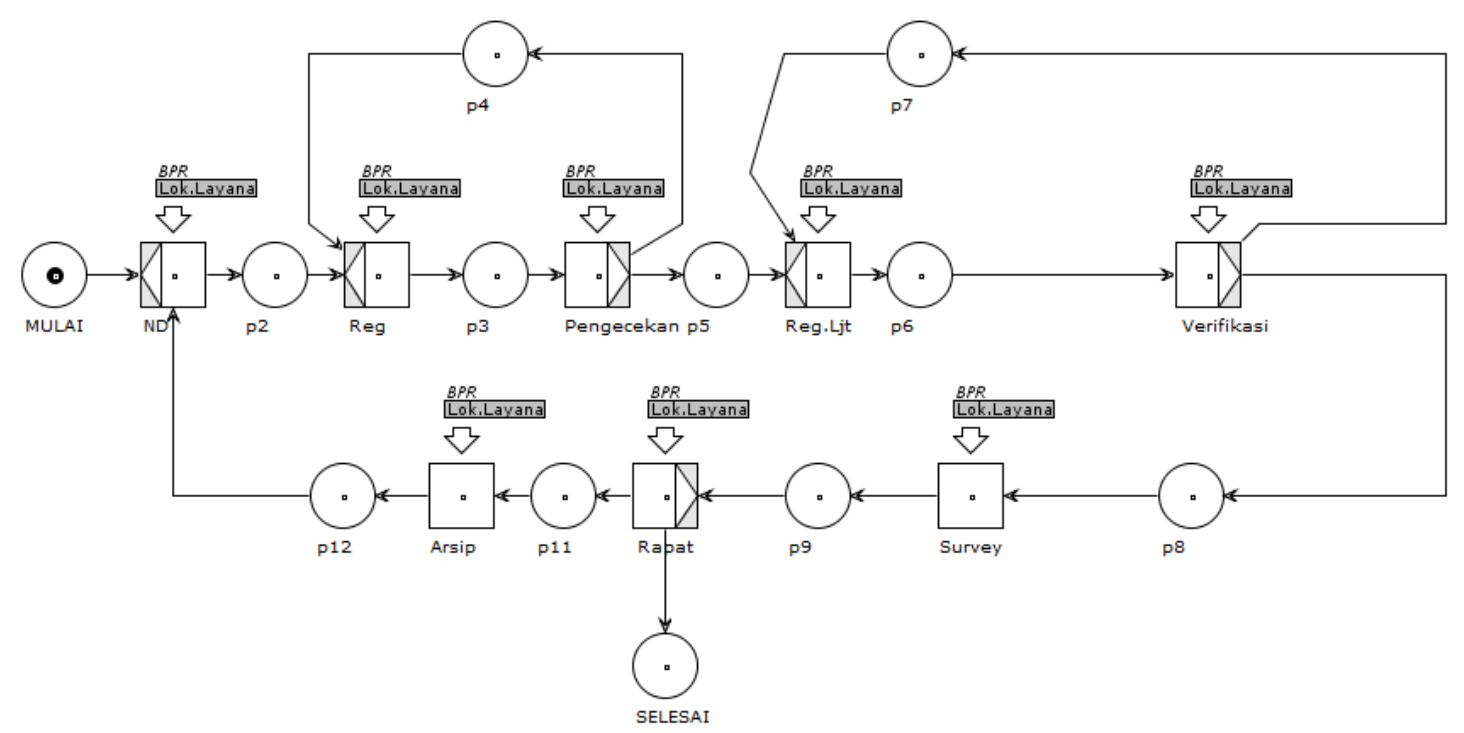

Figure 5. Petri Net Application System for Credit Application Service Process After Repair

The following table shows the results of the analysis of the simulation game token on the WOPED software that has been analyzed.

Table 1. Results of the Game Token Simulation Analysis on WOPED Software

\begin{tabular}{|c|c|c|c|c|}
\hline \multirow{12}{*}{$\begin{array}{l}\text { Qualitative } \\
\text { Analysis }\end{array}$} & \multirow{8}{*}{$\begin{array}{l}\text { Analysis } \\
\text { Structure }\end{array}$} & \multirow{4}{*}{ Not Statics } & Places & 12 \\
\hline & & & Transitions & 8 \\
\hline & & & Operators & 6 \\
\hline & & & Arcs & 22 \\
\hline & & \multicolumn{2}{|c|}{ Wrongly used operators } & Yes \\
\hline & & \multicolumn{2}{|c|}{ Free-choice violations } & Yes \\
\hline & & \multicolumn{2}{|c|}{ S-Components } & No \\
\hline & & \multicolumn{2}{|c|}{ Wellstructuredness } & No \\
\hline & & \multicolumn{2}{|c|}{ Workflow net } & Yes \\
\hline & & \multicolumn{2}{|c|}{ Initial marking } & Yes \\
\hline & Soundness & \multicolumn{2}{|c|}{ Boundness } & Yes \\
\hline & & \multicolumn{2}{|l|}{ Liveness } & No \\
\hline
\end{tabular}

After analyzing with WOPED, it is concluded that the Petri Net for the credit application service process is sound and has the character of well-structuredness and liveness has been fulfilled.

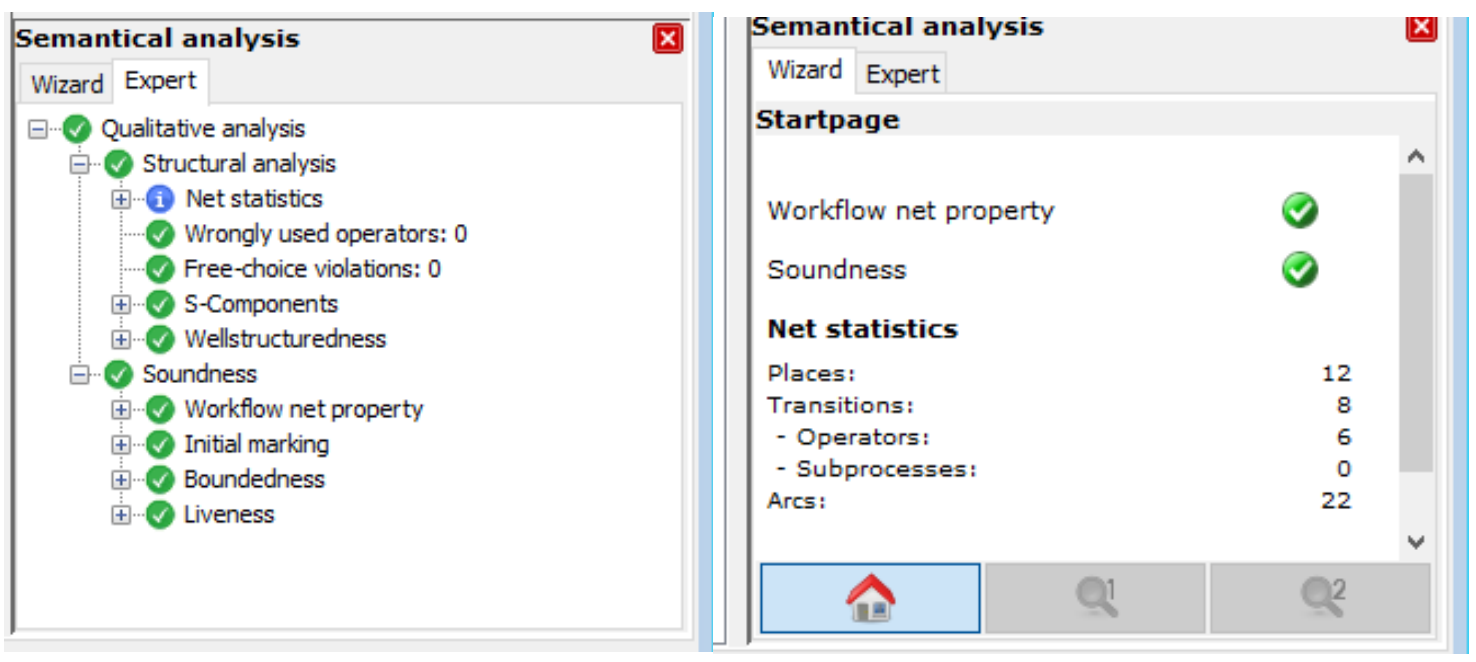

Figure 6. Results of Structural Analysis and Soundness of the Petri Net Credit 


\subsection{Analysis of Processing Time for Credit Application Services at BPR Lambang Ganda Serang}

The following discussion is about the processing time for credit application services at BPR Lambang Ganda Serang. The first process, where the Customer undergoes initial registration, checking the files for initial registration, is carried out by the Credit Administration officer, who takes 15 minutes. The second process, namely checking the completeness of the files by the Financial Services System administrator, takes 15 minutes. The third process, namely the advanced registration carried out by the SLIK administrator, takes 15 minutes. The fourth process, which is waiting for verification by the Executive Officer of Risk Management, takes 10 minutes. The fifth process, namely a survey conducted by a marketing officer, takes 60 minutes. The sixth process, namely a meeting held by the Director and Marketing regarding credit application decisions, takes 20 minutes. Finally, the seventh process, namely waiting for the credit agreement submitted by the Credit Administration officer, takes 30 minutes. Thus, the total time required to apply for credit is 165 minutes.

However, if there are problems regarding failed registration and failed verification, there will be additional time in each process

Table 2. The length of time for the credit application service process

\begin{tabular}{clcc}
\hline \multirow{2}{*}{ Number } & \multicolumn{2}{c}{ Service process } & \multicolumn{2}{c}{ Length of service processing time (minute) } \\
\cline { 3 - 4 } & & Process successful & Process failed \\
\hline 1. & Early registration & 15 & 20 \\
\hline 2. & Completeness file checking & 15 & 20 \\
\hline 3. & Advance registration & 15 & 20 \\
\hline 4. & Verification by executive officer & 10 & 15 \\
\hline 5. & Survey by marketing officer & 60 & 75 \\
\hline 6. & Credit application resolution meeting & 20 & 35 \\
\hline 7. & Waiting for credit agreement & 30 & 45 \\
\hline & Total service processing time & $\mathbf{1 6 5}$ & $\mathbf{2 3 0}$ \\
\hline
\end{tabular}

From Table 2, it is found that the processing time for credit application services that undergo the process successfully takes less time, namely 165 minutes, while those who undergo the process take longer, namely 230 minutes.

Petri Net can be represented in a matrix, namely the forward incidence and backward incidence matrices, which are part of the incidence matrix. The backward incidence matrix element is the arc weight that connects the place to the transition, and the forward incidence matrix element is the arc weight that connects the transition to the place. For example, at Petri Net, in applying for credit at BPR Lambang Ganda, there are 12 places and eight transitions, so that many rows $(n)=12$ and the number of columns $(m)=8$. So that matrices will be formed with a size of $12 \times 8$ with the following representation.

The matrix $A_{b}$ is a backward incidence matrix.

$$
A_{b}=\left[\begin{array}{llllllll}
1 & 0 & 0 & 0 & 0 & 0 & 0 & 0 \\
0 & 1 & 0 & 0 & 0 & 0 & 0 & 0 \\
0 & 0 & 1 & 0 & 0 & 0 & 0 & 0 \\
0 & 1 & 0 & 0 & 0 & 0 & 0 & 0 \\
0 & 0 & 0 & 1 & 0 & 0 & 0 & 0 \\
0 & 0 & 0 & 0 & 1 & 0 & 0 & 0 \\
0 & 0 & 0 & 1 & 0 & 0 & 0 & 0 \\
0 & 0 & 0 & 0 & 0 & 1 & 0 & 0 \\
0 & 0 & 0 & 0 & 0 & 0 & 1 & 0 \\
0 & 0 & 0 & 0 & 0 & 0 & 0 & 0 \\
0 & 0 & 0 & 0 & 0 & 0 & 0 & 1 \\
1 & 0 & 0 & 0 & 0 & 0 & 0 & 0
\end{array}\right]
$$


The matrix $A_{f}$ is a forward incidence

The matrix $A$ is an incidence matrix.

$$
A_{f}=\left[\begin{array}{llllllll}
0 & 0 & 0 & 0 & 0 & 0 & 0 & 0 \\
1 & 0 & 0 & 0 & 0 & 0 & 0 & 0 \\
0 & 1 & 0 & 0 & 0 & 0 & 0 & 0 \\
0 & 0 & 1 & 0 & 0 & 0 & 0 & 0 \\
0 & 0 & 1 & 0 & 0 & 0 & 0 & 0 \\
0 & 0 & 0 & 1 & 0 & 0 & 0 & 0 \\
0 & 0 & 0 & 0 & 1 & 0 & 0 & 0 \\
0 & 0 & 0 & 0 & 1 & 0 & 0 & 0 \\
0 & 0 & 0 & 0 & 0 & 1 & 0 & 0 \\
0 & 0 & 0 & 0 & 0 & 0 & 1 & 0 \\
0 & 0 & 0 & 0 & 0 & 0 & 1 & 0 \\
0 & 0 & 0 & 0 & 0 & 0 & 0 & 1
\end{array}\right]
$$

$$
\begin{gathered}
\text { A }=A_{f}-A_{b} \\
=\left[\begin{array}{cccccccc}
-1 & 0 & 0 & 0 & 0 & 0 & 0 & 0 \\
1 & -1 & 0 & 0 & 0 & 0 & 0 & 0 \\
0 & 1 & -1 & 0 & 0 & 0 & 0 & 0 \\
0 & -1 & 1 & 0 & 0 & 0 & 0 & 0 \\
0 & 0 & 1 & -1 & 0 & 0 & 0 & 0 \\
0 & 0 & 0 & 1 & -1 & 0 & 0 & 0 \\
0 & 0 & 0 & -1 & 1 & 0 & 0 & 0 \\
0 & 0 & 0 & 0 & 1 & -1 & 0 & 0 \\
0 & 0 & 0 & 0 & 0 & 1 & -1 & 0 \\
0 & 0 & 0 & 0 & 0 & 0 & 1 & -1 \\
0 & 0 & 0 & 0 & 0 & 0 & 1 & 0 \\
-1 & 0 & 0 & 0 & 0 & 0 & 0 & 1
\end{array}\right]
\end{gathered}
$$

The backward incidence matrix and forward incidence matrix have matrix elements with a value of 0 and 1, which means that an arc connects the transition to place or place to the transition. Therefore, the matrix element has a value of 1 , whereas if there is no arc connecting the place and transition, the matrix element is worth 0 . The matrix Incidence, whose elements are 0,1 , and -1 , is obtained from reducing the forward incidence matrix and the backward incidence matrix. The values of the matrix elements can differ depending on the arc weight contained in the Petri Net. Furthermore, the backward incidence matrix column can be used to determine which transitions are enabled. The incidence matrix can also be used to determine the following condition.

\section{CONCLUSIONS}

Based on the results, the credit application service process system at BPR Lambang Ganda Serang can be analyzed using the Petri Net model. Moreover, this model controls a discrete event system in the case of a credit application service process system presented mathematically in the form of the Petri Net network. The credit application service process system can be modeled with a Petri Net of 12 places, eight transitions, six operators, and 22 arcs using the Woped software version 3.2.0. From the observations, the length of the credit application service process that undergoes a successful process takes less time, namely 165 minutes, while those who undergo a failed process take longer, namely 230 minutes.

\section{REFERENCES}

[1] A. K. Erlang, "Solution of some Problems in the Theory of Probabilities of Significance in Automatic Telephone Exchanges," Elektrotkeknikeren, vol. 13, 1917.

[2] H. A. Taha, Riset Operasi, Jilid 2. Binarupa Aksara, 1996.

[3] C. A. Petri, "Communication with Automata," Darmstadt Technical University, 1962.

[4] I. Kabashkin, "Modelling of Regional Transit Multimodal Transport Accessibility with Petri Net Simulation," Procedia Comput. Sci., vol. 77, pp. 151-157, 2015. 
[5] I. Kabashkin, "Heuristic Based Decision Support System for Choice of Alternative Routes in the Large-Scale Transportation Transit System on the Base of Petri Net Model," Procedia Eng., vol. 134, pp. 359-364, 2016.

[6] A. Boussif and M. Ghazel, "A Diagnosis Study on a Train Passenger Access System using Petri Net Models," IFACPapers OnLine, vol. 51, no. 9, pp. 150-155, 2018.

[7] J. Zhoua and Reniers. G., "Petri net simulation of multi-department emergency response to avert domino effects in chemical industry accidents," Process Saf. Environ. Prot., vol. 146, pp. 916-926, 2021.

[8] J. Latorre-Biel, J. Faulín, A. A. Juan, and E. Jiménez-Macías, "Petri Net Model of a Smart Factory in the Frame of Industry 4.0," IFAC-PapersOnLine, vol. 51, no. 2, pp. 266-271, 2018.

[9] M. Gheibia, M. Karrabia, and M. Eftekhari, "Designing a smart risk analysis method for gas chlorination units of water treatment plants with combination of Failure Mode Effects Analysis, Shannon Entropy, and Petri Net Modeling," Ecotoxicol. Environ. Saf., vol. 171, pp. 600-608, 2019.

[10] Z. Jianfenga and G. Reniers, "Probabilistic Petri-net addition enabling decision making depending on situational change: The case of emergency response to fuel tank farm fire," Reliab. Eng. Syst. Saf., vol. 200, 2020.

[11] S. Guana, M. Nakamuraa, T. Shikanaib, and T. Okazaki, "Hybrid Petri nets modeling for farm work flow," Comput. Electron. Agric., vol. 62, no. 2, pp. 149-158, 2008.

[12] C. Mahulea, E. Montijano, and M. Kloetzer, "Distributed Multirobot Path Planning in Unknown Maps Using Petri Net Models," IFAC-PapersOnLine, vol. 53, no. 2, pp. 2063-2068, 2020.

[13] Y. Geab, X. Xinga, and Q. Cheng, "Simulation and analysis of infrastructure interdependencies using a Petri net simulator in a geographical information system," Int. J. Appl. Earth Obs. Geoinf., vol. 12, no. 6, pp. 419-430, 2010.

[14] W. Yu, Z. Ding, L. Liu, X. Wang, and R. D. Crossleye, "Petri net-based methods for analyzing structural security in e-commerce business processes," Futur. Gener. Comput. Syst., vol. 109, pp. 611-620, 2020.

[15] P. J. Mitrevski and I. S. Hristoski, "Behavioral-based performability modeling and evaluation of e-commerce systems," Electron. Commer. Res. Appl., vol. 13, no. 5, pp. 320-340, 2014.

[16] R. Munir, Matematika Diskrit. Bandung: Informatika, 2005.

[17] F. N. Wattimena, T. Pentury, and Y. A. Lesnussa, "Aplikasi Petri Net pada sistem pembayaran tagihan listrik PT. PLN (Persero) Rayon Ambon Timur,” BAREKENG J. Ilmu Mat. dan Terap., vol. 6, no. 1, pp. 23-30, 2012.

[18] Subiono, Ajabar Min-Max Plus Dan Terapannya. 2015.

[19] D. Adzkiya, "Membangun Petri Net Lampu Lalu Lintas Dan Simulasinya," Institut Teknologi Sepuluh Nopember Surabaya, 2008.

[20] C. G. Cassandras and S. Lafortune, Introduction to Discrete Event Systems, Second Ed. Boston: Springer Science and Business Media, 1993. 
